\title{
Fe-Ni ALLOY ELECTRODEPOSITION FROM SIMPLE AND COMPLEX TYPE SULFATE ELECTROLYTES CONTAINING Ni/Fe RATIO OF 1 AND 12
}

\author{
M. Moniruzzaman*, K.M. Shorowordi, A. Azam and M.F.N. Taufique \\ Department of Materials and Metallurgical Engineering \\ Bangladesh University of Engineering and Technology (BUET), Dhaka-1000 \\ *Corresponding e-mail: mmoniruzzaman@mme.buet.ac.bd
}

\begin{abstract}
Iron-nickel (Fe-Ni) alloy electrodeposition has been conducted from simple and complex baths having $\mathrm{Ni} / \mathrm{Fe}$ ratio of 1 and 12. The applied current density varies from 30 to $100 \mathrm{~mA} / \mathrm{cm}^{2}$. The coating composition, morphology and microhardness are measured and characterized by SEM/EDX and Shimadzu microhardness tester. The percentage of $\mathrm{Ni}$ in the coating increases with increasing current density and the $\mathrm{Ni} / \mathrm{Fe}$ ratio of electrolytes which is supported by the alloy deposition principle. Fine grained and smooth coating without microcracking is obtained from the complex baths. Complexing agents are supposed to reduce the deposit stress developed during electrodeposition. Increase in Ni/Fe ratio in the bath as well as current density results in decreasing grain size of the deposits. High current density is believed to give rise to a high degree of adatoms at the electrode surface and high degree of adatoms decreases the grain size. Microhardness of the coating increases with the increase of bath $\mathrm{Ni} / \mathrm{Fe}$ ratio as well as current density of electrodeposition.
\end{abstract}

Keywords: Anomalous electrodeposition, Fe-Ni alloy coating, Complex bath, Current density.

\section{INTRODUCTION}

Alloy electrodeposition technologies can extend tremendously the potential of electrochemical deposition processes to provide coatings that require unique mechanical, chemical and physical properties ${ }^{1}$. There has been a great research interest in the development and characterization of iron-nickel (Fe$\mathrm{Ni}$ ) thin films due to their operational capacity, economic interest and unique properties ${ }^{2}$. The properties, the composition and the grain size of electrodeposited Fe-Ni alloys are strongly dependent on the electrolyte composition, applied current density, bath $\mathrm{pH}$, temperature, agitation etc. $\mathrm{Fe}-\mathrm{Ni}$ alloy electrodeposition exhibits the phenomenon of anomalous codeposition. This term introduced by Brenner $^{3}$ is being used to describe the preferential deposition of the less noble metal, $\mathrm{Fe}$, to the more noble metal, $\mathrm{Ni}$. In other words, the reduction of $\mathrm{Ni}$ is inhibited while the deposition of $\mathrm{Fe}$ is enhanced when compared with their individual deposition rates. Thus electrodeposition of $\mathrm{Fe}-\mathrm{Ni}$ alloys has attracted considerable attention because of its special characteristic nature and wide range of unique properties. An important feature of the Fe-Ni alloy system is its structural evolution, with a change from bcc for the Fe-rich alloy to fcc for the alloy with higher $\mathrm{Ni}$ content $^{4}$. $\mathrm{Fe}-\mathrm{Ni}$ alloys ranging in composition from Invar $\left(\mathrm{Ni}_{36} \mathrm{Fe}_{64}\right)$ to Permalloy $\left(\mathrm{Ni}_{81} \mathrm{Fe}_{19}\right)$ exhibit a spectrum of physical properties that have led to the widespread use of these materials in a variety of high technology applications ${ }^{5-8}$.

In spite of the importance of $\mathrm{Fe}-\mathrm{Ni}$ alloy electrodeposition, addition of complexing agents in the bath and their interactions with the plating parameters on the properties of electrodeposited $\mathrm{Fe}-\mathrm{Ni}$ alloy has received little attention so far. Previous study shows the effects of complexing agents and current density on electrodeposition of Fe-Ni alloy'. In the present work, baths containing sulfate salts with $\mathrm{Ni} / \mathrm{Fe}$ ratio of low and high value including complexing agent and current density have been studied systematically.

\section{EXPERIMENTAL}

Commercial copper $(\mathrm{Cu})$ sheets were used as substrates in the experiment of this study. Platinum anodes were used for electrodeposition. Dimension of the $\mathrm{Cu}$ substrate was $50 \mathrm{~mm} \times 15 \mathrm{~mm} \times 1 \mathrm{~mm}$. The $\mathrm{Cu}$ substrates were degreased, mechanically and electrochemically cleaned by maintaining polishing with emery papers, pickling, rinsing and acid dipping process. Electrodeposition was carried out in a laboratory type electrodeposition set-up consisting of a beaker, a D.C. power supply, cathode and anode electrodes. Two platinum anodes were used at equal distance on both sides of the cathode for uniform deposition on both sides of the cathode.

Both simple and complex baths were used. Analytical reagent grade chemicals and deionized water were used to prepare baths. Sulfate baths composing of $\mathrm{NiSO}_{4}, 7 \mathrm{H}_{2} \mathrm{O} ; \mathrm{FeSO}_{4}, 7 \mathrm{H}_{2} \mathrm{O} ; \mathrm{H}_{3} \mathrm{BO}_{3}$ and $\mathrm{Na}_{2} \mathrm{SO}_{4}$ in varying composition comprise the simple baths where $\mathrm{Ni} / \mathrm{Fe}$ ratio was maintained 1 and 12 . One complex bath was prepared by adding only ascorbic acid and another complex bath was prepared by adding ascorbic acid, saccharin and citric acid in the simple bath. $\mathrm{Ni} / \mathrm{Fe}$ ratio of both complex baths was maintained 12. Details of the simple and complex bath 
compositions are shown in Table 1.

All depositions were carried out at room temperature and at current densities of 30, 50, 70 and $100 \mathrm{~mA} / \mathrm{cm}^{2}$. Each deposition was continued for a predetermined time period of 2 hours without any stirring action. Scanning Electron Microscopy (SEM) was used to study the morphology of Fe-Ni alloy coatings. Chemical composition of the deposit was determined by energy dispersive $\mathrm{x}$-ray (EDX) analyzer. Microhardness indentations were imposed on the coating surface by using a Shimadzu Microhardness Tester. A load of $25 \mathrm{~g}$ was applied for 10 seconds on unetched specimen surface of $\mathrm{Fe}-\mathrm{Ni}$ alloy coating.

Samples of Bath B-2 (at current density 100 $\mathrm{mA} / \mathrm{cm}^{2}$ ) were heat-treated in inert atmosphere for 40 minutes at the temperature range of $350^{\circ} \mathrm{C}$ to $500^{\circ} \mathrm{C}$ and then the effect of heat-treatment on the coating morphology and microhardness (VHN) was studied.

Table 1. Plating Bath composition for the electro-deposition of Fe-Ni alloy coating

\begin{tabular}{|c|c|c|c|}
\hline \multirow{2}{*}{$\begin{array}{l}\text { Bath } \\
\text { identification }\end{array}$} & \multicolumn{2}{|c|}{ Bath composition } & \multirow{2}{*}{$\mathrm{Ni} / \mathrm{Fe}$ ratio } \\
\hline & Principal ingredients $(\mathrm{g} / \mathrm{L})$ & Complexing ingredients $(\mathrm{g} / \mathrm{L})$ & \\
\hline B-1a (simple) & $\begin{array}{l}\mathrm{NiSO}_{4} .7 \mathrm{H}_{2} \mathrm{O}=28.1 \\
\mathrm{FeSO}_{4} .7 \mathrm{H}_{2} \mathrm{O}=27.8 \\
\mathrm{H}_{3} \mathrm{BO}_{3}=12.4\end{array}$ & ------ & 1 \\
\hline B-1b (simple) & \multirow{3}{*}{ 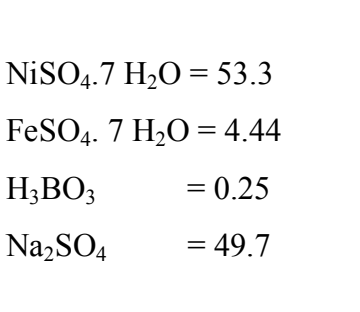 } & ------ & \multirow{3}{*}{12} \\
\hline B-2 (complex) & & ascorbic acid $=4$ & \\
\hline B-3 (complex) & & $\begin{array}{l}\text { ascorbic acid }=4 \\
\text { citric acid }=4 \\
\text { saccharine }=4\end{array}$ & \\
\hline
\end{tabular}

\section{RESULTS AND DISCUSSION}

\section{Chemical Analysis of the Deposit}

Two simple and two complex baths were used in this study. Effect of bath $\mathrm{Ni} / \mathrm{Fe}$ ratio concentration on coating can be obtained from baths B-1(a), B-1(b) whereas effect of complexing agents on coating at high $\mathrm{Ni} / \mathrm{Fe}$ ratio can be obtained from baths $\mathrm{B}-2$ and B-3 (Table 1).

Chemical analysis of the coatings was carried out by the SEM equipped with EDX. Fe-Ni films obtained at different current densities from baths with varying $\mathrm{Ni} / \mathrm{Fe}$ ratio showed the variation of $\mathrm{Ni}$ content in it (Fig. 1). It was observed that at low Ni/Fe ratio (B-1a), the percentage of $\mathrm{Ni}$ in deposited layer was lower than that of the layer deposited from the high $\mathrm{Ni} / \mathrm{Fe}$ ratio (B-1b, B-2 and B-3). It was also seen that the percentage of $\mathrm{Ni}$ in the deposited layer increased with increasing applied current density for all bath composition at high $\mathrm{Ni} / \mathrm{Fe}$ ratio. Good deposition could not be obtained from the simple baths B-1(a) and B-1(b) at $30 \mathrm{~mA} / \mathrm{cm}^{2}$. Thus good quality deposition at low current density was only possible from complex baths.

Simple Bath-1(a) contains lower $\mathrm{Ni} / \mathrm{Fe}$ ratio in its electrolyte composition than the other three baths. The highest $\mathrm{Ni}$ content in the deposit was measured as $11.09 \mathrm{wt} \%$ for bath B-1(a) at the current density of
$100 \mathrm{~mA} / \mathrm{cm}^{2}$ while $92.29,92.34$ and $90.59 \mathrm{wt} \% \mathrm{Ni}$ content was found for bath B-1(b), B-2 and B-3 respectively at the same current density. This is supported by the alloy deposition principle that an increase in the metal percentage (or ratio) of a parent metal in an alloy plating bath results in an increase in its percentage (or ratio) in the deposit ${ }^{10}$. Moreover, the electrolyte conductance increases as a result of addition of $\mathrm{Na}_{2} \mathrm{SO}_{4}$ in bath B-1(b), B-2, B-3 and consequently it significantly increased $\mathrm{Ni}^{2+}$ in the deposit if compared with bath B-1(a) ${ }^{9}$. Here, the minimum $\mathrm{Ni}$ content $(67.94 \%)$ of coatings obtained from all baths containing $\mathrm{Ni} / \mathrm{Fe}$ ratio 12 is higher than the maximum Ni content $(11.09 \%)$ of those obtained from bath containing $\mathrm{Ni} / \mathrm{Fe}$ ratio 1 .

The standard electrode potential for reduction of pure $\mathrm{Ni}^{2+}(-0.257 \mathrm{~V})$ is relatively more positive than that of $\mathrm{Fe}^{2+}(-0.447 \mathrm{~V})$. According to normal deposition theory, an element with a higher positive standard electrode potential is expected to deposit preferentially than the one with a less positive standard electrode potential ${ }^{11,12}$. Again according to Brenner's definition of anomalous codeposition ${ }^{3}$, the less noble metal (here Fe) is deposited preferentially and its percentage in the deposit become higher than that in electrolytes. Fe-Ni alloy electrodeposition is recognized as anomalous co-deposition but under 
some conditions of current density and temperature, $\mathrm{Fe}-\mathrm{Ni}$ metals may also co-deposit in a normal fashion. Figure 2 shows the relation between $\% \mathrm{Ni}$ (more noble metal) in the deposit and \% $\mathrm{Ni}$ in the bath. The feature of this figure is that the composition points for the more noble metals, $\mathrm{Ni}$, lie below the composition reference line, $\mathrm{AB}$, which means that the less noble metal deposits preferentially under the test conditions in this study. Thus, Fe-Ni alloy shows anomalous electrodeposition in the test conditions of this study. Point C (corresponding to the complex bath B-3) is closer to the reference line, $\mathrm{AB}$, than the other two composition points indicating that higher \% Ni (more noble) in coatings deposited from complex bath than the simple baths. This concludes that addition the complexing agents suppresses the anomalous nature of the Fe-Ni alloy electrodeposition.

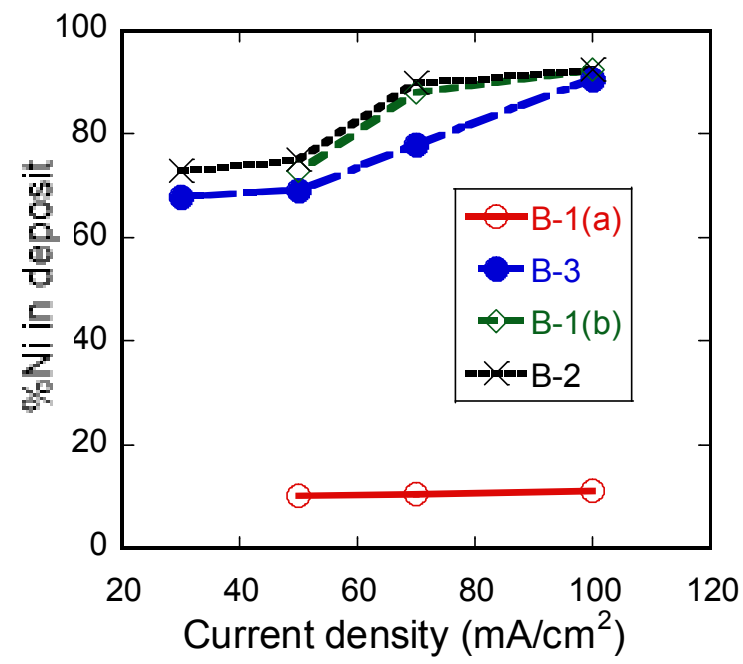

Figure 1. Effect of current density on $\% \mathrm{Ni}$ in coating deposited from all the experimental baths.

\section{Morphology of the Coating}

The influence of bath composition with current density on the morphology of Fe-Ni coatings was evaluated by Scanning Electron Microscope (SEM). The topographies of $\mathrm{Fe}-\mathrm{Ni}$ coatings were analyzed concerning their uniformity, grain size and the presence/absence of cracks.

SEM micrographs of $\mathrm{Fe}-\mathrm{Ni}$ alloy coatings electrodeposited at current density of $70 \mathrm{~mA} / \mathrm{cm}^{2}$ both from simple and complex baths are shown in Fig. 3. Bath-1a and bath-1b are simple baths with electrolytes containing $\mathrm{Ni} / \mathrm{Fe}$ ratio of 1 and 12 respectively. Grain size in Fig. $3 \mathrm{a}$ is $\sim 6 \mu \mathrm{m}$ and that in Fig. $3 \mathrm{~b}$ is $\sim 3 \mu \mathrm{m}$. Thus grain size decreased in coating obtained from bath having higher $\mathrm{Ni} / \mathrm{Fe}$ ratio. Moreover, morphology of the $\mathrm{Fe}-\mathrm{Ni}$ alloys obtained from the simple baths is characterized by the presence of sharp-

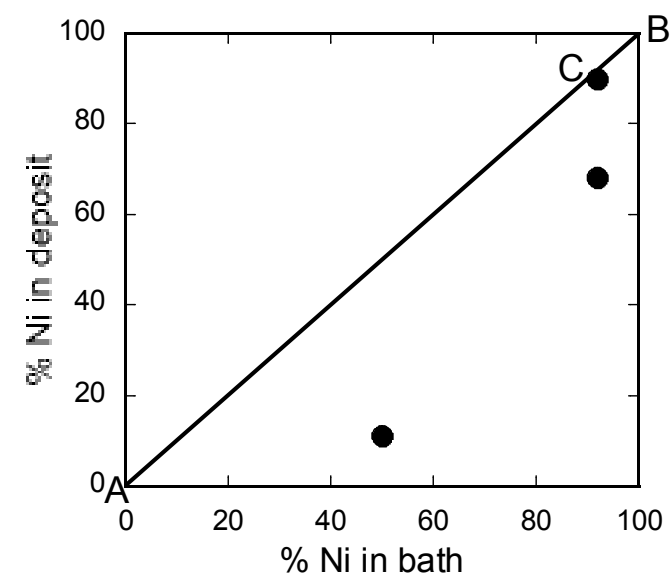

Figure 2. Relation between the composition of the deposit and the composition of the bath in Fe-Ni codeposition from the baths under test.

line microcracks distributed over the deposits. The stress developed during electrodeposition is supposed to be attributed for the microcracks. On the contrary, microcracks could not be seen in the deposits obtained from complex baths (Fig. 3c and 3d).

Figures 4 and 5 show SEM images of Fe-Ni alloy coatings obtained from high $\mathrm{Ni} / \mathrm{Fe}$ ratio complex baths B-2 and B-3 respectively at different current density. Grains of coatings obtained from bath B-2 containing only ascorbic acid as complexing agent are relatively smaller than those obtained from bath B-3 containing all three complexing agents. Grains are roughly spherical and average grain size decreases with increasing current density. Change in grain size is more prominent in coatings deposited from bath B3 containing all three complexing agents. Thus structure of the Fe-Ni coatings is strongly influenced by current density. Myung et al. ${ }^{13}$ reported similar observations to binary Fe-Ni thin films.

Morphology of the deposits can be controlled by using electrolytes containing complexing agent/agents with proper compositions. For complexing agent, the crystallization of the electrodeposited layer is very important, since it influences directly the structure of the deposit and therefore its properties ${ }^{14}$. Crystallization occurs either by the buildup of old crystals or by the formation and growth of new ones. These two processes are in competition and can be influenced by different factors. High surface diffusion rates, low population of adatoms and low overpotentials are factors enhancing the buildup of old crystals. On the contrary, low surface diffusion rates, high population of adatoms and high over-potentials on the surface enhance the creation of new nuclei ${ }^{15}$. From the SEM observations, it can be said that addition of complexing agent of $4.0 \mathrm{~g} / 1$ ascorbic acid 

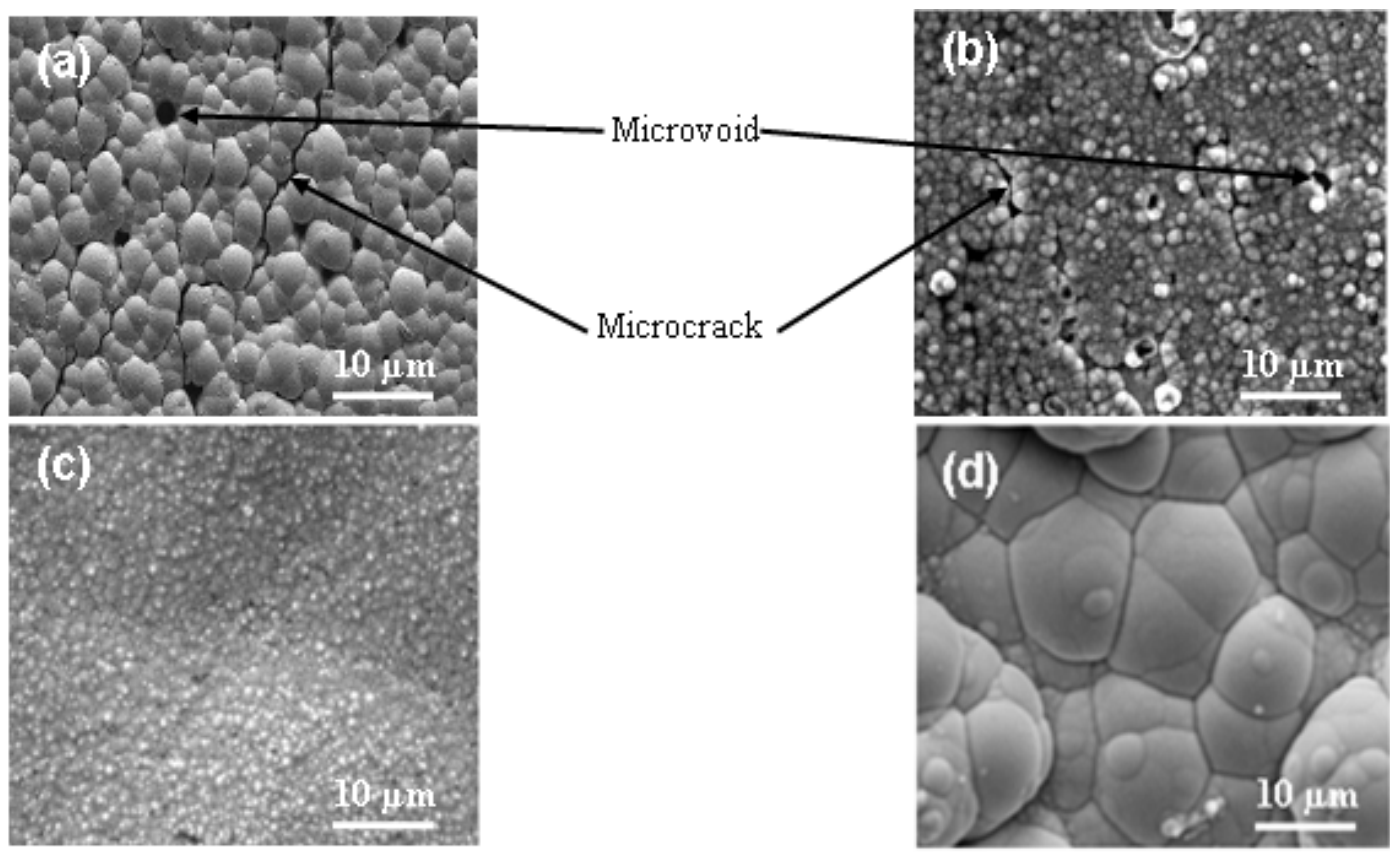

Figure 3. SEM micrographs of Fe-Ni alloy coatings electrodeposited at current density of $70 \mathrm{~mA} / \mathrm{cm}^{2}$ from (a) Bath-1(a), (b) Bath-1(b), (c) Bath-2 and (d) Bath-3
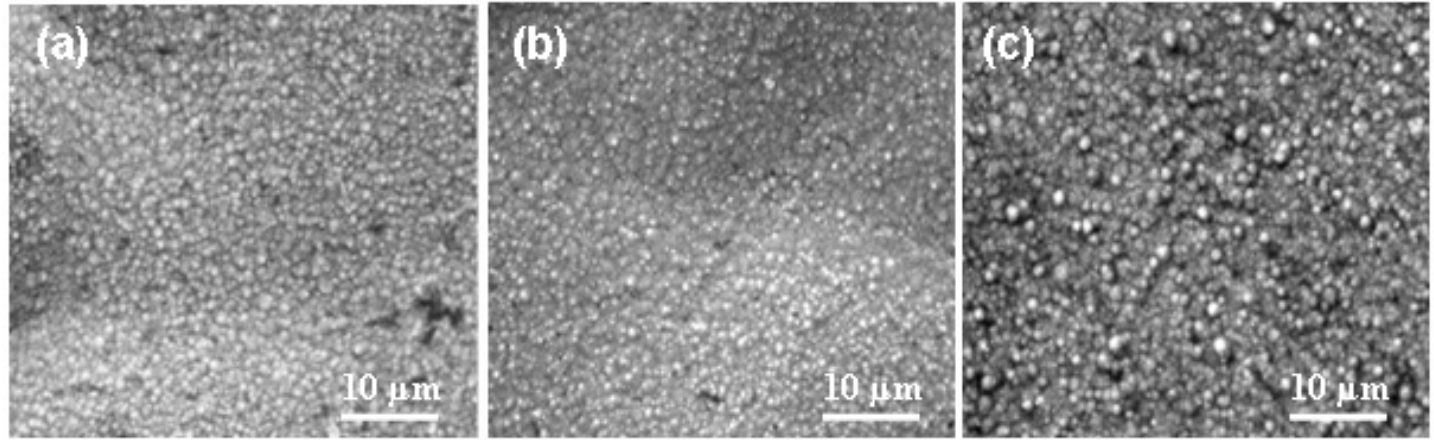

Figure 4. SEM micrographs of Fe-Ni alloy coatings electrodeposited from complex bath B-2 at current density of (a) $100 \mathrm{~mA} / \mathrm{cm}^{2}$ (b) $70 \mathrm{~mA} / \mathrm{cm}^{2}$ and (c) $30 \mathrm{~mA} / \mathrm{cm}^{2}$
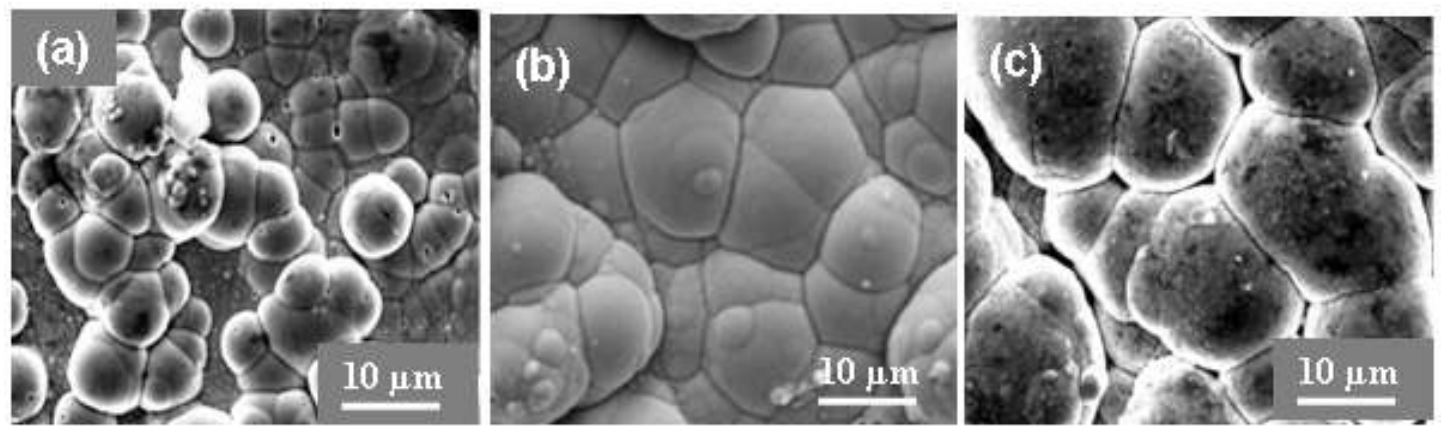

Figure 5. SEM micrographs of Fe-Ni alloy coatings electrodeposited from complex bath B-3 at current density of (a) $100 \mathrm{~mA} / \mathrm{cm}^{2}$ (b) $70 \mathrm{~mA} / \mathrm{cm}^{2}$ and (c) $30 \mathrm{~mA} / \mathrm{cm}^{2}$

Journal of Mechanical Engineering, Vol. ME 44, No. 1, June 2014

Transaction of the Mechanical Engineering Division, The Institution of Engineers, Bangladesh 
increased nucleation rates that helped to form crackfree, uniform and fine grained structures as is seen in Fig. 3c whereas coarse grain morphology (Fig. 3d) is seen in deposit obtained from bath B-3. High surface diffusion rates, low population of adatoms and low over-potentials are believed to be predominant in case of bath B-3 containing all three complexing agents.

It is known that high current density give rise to a high degree of adatoms saturation at the electrode surface, and high degree of adatoms increases the crystallization and thus decreases the grain size. After heat treatment of the electrodeposited samples, the grain size was measured again. The average grain size increased after heat treatment than before. The grain size increment with annealing temperature is shown in Fig. 6.

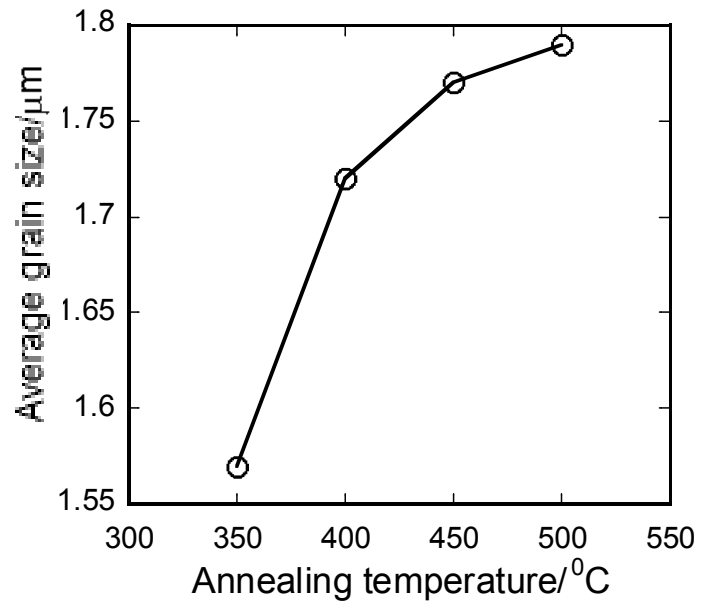

Figure 6. Effect of annealing temperature on average grain size in coating deposited from bath B-2 at current density of $100 \mathrm{~mA} / \mathrm{cm}^{2}$

\section{Microhardness of the Coating}

Vickers Hardness Number (VHN) of the deposits was evaluated by microhardness testing using a Shimadzu microhardness machine. It was found that the hardness of Fe-Ni alloy deposited from high $\mathrm{Ni} / \mathrm{Fe}$ ratio containing bath was higher than the alloy deposited from the low $\mathrm{Ni} / \mathrm{Fe}$ ratio containing bath. It is reported that $\mathrm{Ni}$ is harder than $\mathrm{Fe}^{16}$. As Ni percentage in the alloy deposited from high $\mathrm{Ni} / \mathrm{Fe}$ ratio was higher (Fig. 1), it yielded high hardness. Figure $7 \mathrm{a}$ showed microhardness of the coatings deposited from complex bath B-2 as a function of applied current density in the deposition process. Microhardness increased with increasing current density as $\% \mathrm{Ni}$ in the deposit increased with increasing current density. Increasing annealing temperature results the decrease of $\mathrm{VHN}$ of the deposits (Fig. 7b). Annealing softens the coating. Before annealing the VHN of the coating deposited at
$100 \mathrm{~mA} / \mathrm{cm}^{2}$ from bath B-2 was 778 and the same sample showed $270 \mathrm{VHN}$ after annealing at $500^{\circ} \mathrm{C}$.
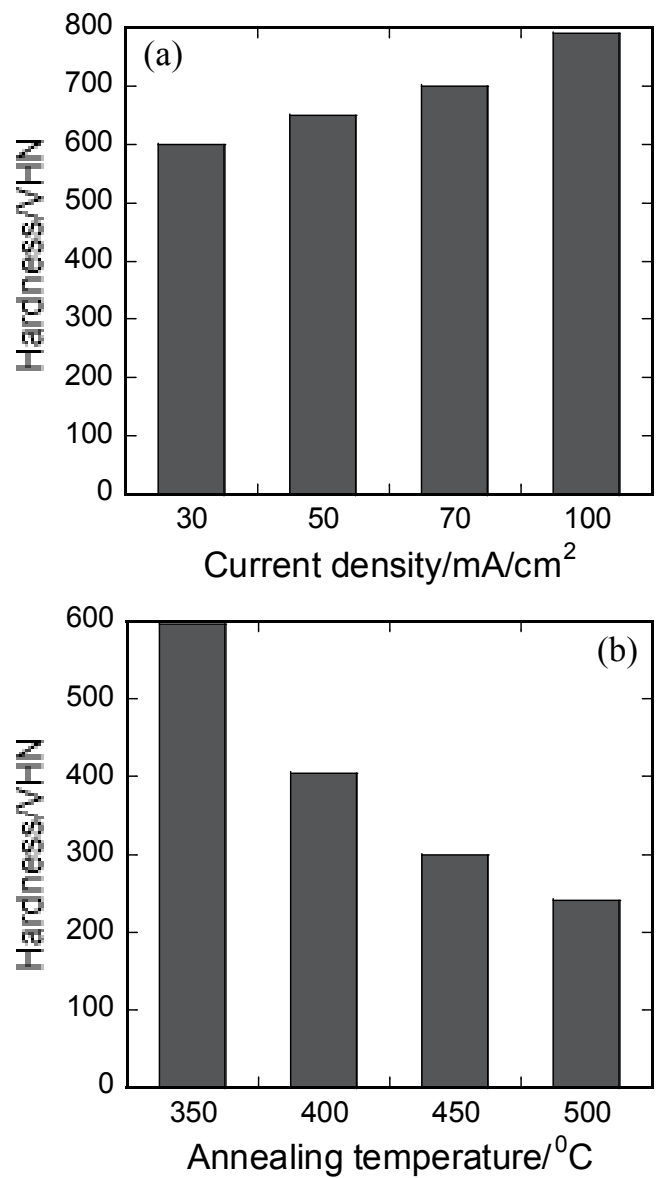

Figure 7. Microhardness as a function of (a) current density and (b) annealing temperature of the coating obtained from bath B-2 (current density of 100

$$
\left.\mathrm{mA} / \mathrm{cm}^{2}\right)
$$

\section{CONCLUSIONS}

Electrodeposition of $\mathrm{Fe}-\mathrm{Ni}$ thin films has been carried out on copper substrate under various electrodeposition conditions from simple as well as complex baths. The $\mathrm{Ni} / \mathrm{Fe}$ ratio in bath composition with current density is considered as varying parameters in this work. The conclusions drawn from the study are:

- The percentage of $\mathrm{Ni}$ in the $\mathrm{Fe}-\mathrm{Ni}$ alloy coating deposited from electrolytes containing high $\mathrm{Ni} / \mathrm{Fe}$ ratio is higher than that of the coating deposited from low $\mathrm{Ni} / \mathrm{Fe}$ ratio and the percentage of $\mathrm{Ni}$ into the coating increases with increasing current density. This is supported by the alloy deposition principle. 
- The morphology of the Fe-Ni films obtained from simple baths is characterized by non-smooth surface with presence of microcracks onto it. On the contrary, coatings from complex baths are finegrained with smooth surfaces which may be attributed to the addition of complexing agents as they act as stress reliever.

- Increase in $\mathrm{Ni} / \mathrm{Fe}$ ratio in the bath as well as current density decrease grain size of the deposits. High current density is believed to give rise to a high degree of adatoms saturation at the electrode surface and high degree of adatoms decreases the grain size.

- Percentage $\mathrm{Ni}$ and hence VHN of the coating increase with increasing $\mathrm{Ni} / \mathrm{Fe}$ ratio and current density. With increasing annealing temperature, VHN decreases as the grain size along with softening of the samples increases.

\section{ACKNOWLEDGEMENTS}

The authors like to thank the head of the Project of Development of Materials for Tools and Bio Metallic Implant (DMTBI), Bangladesh Council of Scientific and Industrial Research (BCSIR) for allowing their laboratory facility. Bangladesh Atomic Energy Commission (BAEC) is also gratefully acknowledged for getting facility of using their SEM and EDX.

\section{REFERENCES}

1. Landolt, D., 2002, "Electrodeposition Science and Technology in the Last Quarter of the Twentieth Century", J. Electrochem. Soc, 149 (3), pp. S9-S20.

2. Li, H. and Ebrahimi, F., 2003, "Synthesis and Characterization of Electrodeposited Nanocrystalline Nickel-Iron Alloys", Mater. Sci. Eng. A, 347, pp. 93101.

3. Brenner, A., 1963, "Electrodeposition of Alloys 2", Academic Press, New York.

4. Abrikosov, I. A., Eriksson, O., Soderlind, P., Skriver, H., L., and Johansson, B., 1995, "Theoretical Aspects of the $\mathrm{Fe}_{\mathrm{c}} \mathrm{Ni}_{1-\mathrm{c}}$ Invar Alloy", J. Phys. Rev. B, 51, pp. 1058-1063.

5. Gobet, J., Cardot, F., Bergqvist, J., and Rudolf, F., 1993, "Electrodeposition of 3D Microstructures on Silicon”, J. Micromech Microeng, 3, pp.123-130.
6. Andricacos, P. C., Romankiw, L, T., Gerisher, H., and Tobias, C. H., 1994 "In Advances Electrochemical Science and Engg. 3", VCH. New York, U.S A.

7. Lochel, B., Maciossek, A., Quenzer, H., J., and Wagner, B., 1996, "Ultraviolet Depth Lithography and Galvanoforming for Micromachining", J. Electrochem. Soc, 143(1), pp. 237-244.

8. Romankiw, L. T.,1997, "A Path: from Electroplating Through Lithographic Masks in Electronics to LIGA in MEMS", Electrochim. Acta, 42, pp. 2985-3005.

9. Moniruzzaman, M., and Islam, M. A., 2012,"Effects of Bath Composition and Current Density on the Electrodeposition of Fe-Ni Alloy on Copper Substrate and the Property of Deposited Alloy”, Bangladesh J. Sci. Ind. Res, 47(4), pp. 379386.

10. Brenner, A., 1963, "Electrodeposition of Alloys I", Academic Press, London.

11. Abu-Krisha, M. M., Zaky, A. M., and Toghan, A. A., 2006, "Morphology, Composition and Corrosion Properties of Electrodeposited Zn-Ni Alloys from Sulphate Electrolytes", Asian J. of Biochem, 1(1), pp. 84-97.

12. Moniruzzaman, M., Rakib, M. M., and Matin, F., T., 2012,“Cr-Ni Alloy Electrodeposition and Comparison with Conventional Pure $\mathrm{Cr}$ Coating Technique", Int. J. of Auto and Mech. Engg, 6, pp. 692-700.

13. Myung, N. V., Park, D. Y., Urgiles, D. E., and George, T., 2004, "Electroformed Iron and FeCo Alloy", Electrochim. Acta, 49, pp. 4397-4404.

14. Marder, A. R., and Flaman, A. M., 2004, "Characterization of Copper-Zinc Alloys Produced in Sulphate Electrolytes", J. Materials Research, 8, pp. 285-299.

15. Ebrahimi, F., and Li, H., Q., 2003, "Structure and Properties of Electrodeposited Nanocrystalline FCC Ni-Fe Alloys", J. Rev. Adv. Mater. Sci, 5, pp.134138.

16. Samsonov, G. V., 1968, "Handbook of the Physicochemical Properties of the Elements", IFIPlenum, New York, USA. 